\title{
Neural correlates of placebo effect: Review and future implications
}

\author{
Plasebo etkisinin nöral temelleri: Geçmiş bulguların gözden geçirilmesi ve çıkarsamalar
}

\section{Sezin Öner ${ }^{1}$}

\begin{abstract}
Experimental and clinical research has documented expectancy related symptom improvement in a variety of conditions, leading to a growing interest in the placebo effect. Despite significant treatment outcomes, placebo-induced effects have been regarded as nonspecific psychological factors associated with the subjective experience of healing that operates different than the actual drug agent . However, neuroimaging research revealed more complex regulation of the placebo response, which indicates a top-down regulation of the symptom improvement enhanced by the expectancy effects. It appears that, placebo response is not solely function of higher order control processes, but also involves diverse disease-specific neurobiological mechanisms. In the current review, neural mechanisms underlying placebo effect have been addressed focusing on the analgesia, Parkinson's disease and major depression. Along with the opiate system, dopaminergic and serotonergic functions in the brain are discussed in relation with the three target conditions. Last, potential implications of the placebo research are discussed with respect to experimental and clinical practice.
\end{abstract}

Keywords: placebo effect, pain, antidepressants, Parkinson's disease, treatment expectancy

Öz

İyileşme beklentisi ile ilişkili hastalığa-özgü semptomlardaki iyileşme literatürde sıkça gösterildiğinden plasebo etkisine olan ilgi giderek artmaktadır. Her ne kadar tedavi etkinliği plasebo gruplarında belirgin olsa da, bu etkinin asıl maddeden ziyade, hastanın iyileşme beklentisi ve öznel iyilik değerlendirmesinin bir sonucu olarak düşünülmektedir. Öte yandan, beyin görüntüleme çalışmaları daha karmaşık bir sürecin var olduğuna işaret etmektedir. Denetimli kontrol mekanizmalarının yönettiği plasebo etkisinin iyileşme beklentisi ile güçlendiği görüşü giderek ağırlık kazanmaktadır. Bu bağlamda görünen odur ki, plasebo etkisi tek bir sistem üzerinden değil, hastalık temelli mekanizmalar aracılı̆̆ı ile ortaya çıkmaktadır. $\mathrm{Bu}$ derleme çalışmasında da, plasebo etkisinin nöral boyutlarının sıkça incelendiği ağrı, Parkinson ve depresyon olgularına ilişkin bulgulara odaklanılmış ve opiat sistemi ile dopaminerjik ve serotonerjik işlevler incelenmiştir. Bu doğrultuda da, geçmiş bulguların gözden geçirilmesinin ardından plasebo etkisinin gelecek çalışmalardaki rolü tartışılmışıtır. Anahtar sözcükler: Plasebo etkisi, ağrı, antidepresanlar, Parkinson, tedavi beklentisi

\section{Introduction}

The notion of placebo effect refers to the positive outcome of a treatment that is known to have no particular effect for the condition being treated; but the resulting treatment response acts as if the patients have received an active, effective treatment for the particular condition [1]. A number of studies have addressed the mechanisms underlying placebo effect and current evidence highlight the learning and expectancy related outcomes [2,3], yet there is still much to be uncovered. A number of confounding factors have been implicated both in the methodology and design employed in empirical studies [46]. Individual differences in placebo responsiveness, disease-specific outcomes and difficulty of testing nonspecific psychological factors further blur the conclusions drawn from the symptom improvement. On the other hand, use of neuroimaging techniques, such as functional magnetic resonance imaging (fMRI), positron emission tomography (PET), allowed researchers to objectively examine the course of placebo-induced 'healing' when it exists. But more importantly, this line of research revealed the neural mechanisms through the course of placebo effect and how the outcome is modulated by the higher-order
Koc University, Faculty of Psychology, Istanbul, Turkey. Koç Üniversitesi, Psikoloji AD, İstanbul, Türkiye

Conflict of Interest: No conflict of interest was declared by the authors.

Çıkar Çatışması: Yazarlar çıkar çatışması bildirmemişlerdir.

Financial Disclosure: The authors declared that this case has received no financial support.

Finansal Destek: Yazarlar bu olgu için finansal destek almadıklarını beyan etmişlerdir.

Geliş Tarihi / Received

20.04.2017

Kabul Tarihi / Accepted

27.05.2017

Yayın Tarihi/Published

15.08 .2017

Sorumlu yazar / Corresponding author

Sezin Oner

Address: Department of Psychology, Koç University, Rumelifeneri

Yolu 34450 Sarıyer, Istanbul, Turkey.

Tel: +90531505 5979

E-posta:soner@ku.edu.tr

(c) Copyright 2017 ACEM

cognitive processes. Accordingly, current review outlined the major evidence on the neurobiology of the placebo effect. Although clinical trials on any clinical conditions consider placebo effect, neuroimaging data mostly comes from analgesia, Parkinson's disease and depression, thus, here the focus is limited to these particular conditions.

\section{Pain and Placebo Analgesia}

In general terms, pain is the natural physical response of the organism, placebo analgesia is the voluntary modulation of pain, either consciously or nonconciously [1]. Converging evidence demonstrated that central nervous system, through its diverse connections to internal body parts and sense organs. Recent brain imaging research has revealed that sensory intensity and subjective experience associated with pain are processed by separate mechanisms such that somatosensory cortex and mainly the insula lead the sensory experience whereas affective experience of pain is modulated by anterior cingulate cortex $[7,8]$. 
The mechanism for placebo analgesia was first shown by injection of naloxone to patients after the administration of active and placebo treatments ${ }^{1}$. They found that naloxone impaired the analgesic affects of placebo that subjects who in that group experienced increased postoperative pain. As naloxone being an opioid antagonist, the very early explanations of the placebo effect focused on the opioid receptors. Subsequent studies pointed out the role of specific brain regions and neurochemicals underlying placebo analgesia. For example, Petrovic et al. [9] compared healthy adults for their responses to thermal pain in saline (placebo) and remifentanil, a short acting opioid analgesic drug. Verbal instructions were exactly the same in order to eliminate expectancy-related outcomes. They found increased opioid related activity in right ACC (anterior cingulate cortex) and OFC (orbitofrontal cortex) for both conditions In addition to this, overlapping activity was observed in regions of right ACC, periaqueductal gray matter (PAG) and pons in both groups, suggesting for the comparable opioid mechanisms activated to reduce pain in response to active and placebo treatments that placebo analgesia involves the same opioid activations with the active drug effects to decrease pain experience. However, different from the active drug condition, for the placebo group, higher opiate activity observed in right ventrolateral prefrontal cortex (VLPFC) underlined the top-down control of placebo-induced analgesia. Zubieta et al.[10] provided confirming evidence using a PET scan in a group of participants under sustained pain. Specifically, they examined changes associated with carfentanil, a potent opioid analgesic competing with endogenous opioid receptors. Changes in the opioid release were tested in relation with placebo analgesia. Placebo treatment resulted in the down-regulation of opioid receptors in both cortical and subcortical structures such as dorsal ACC, lateral PFC, insula, nucleus accumbens (NAcc), thalamus and amygdala. Sustained pain paradigm was tested also using a different experimental design in which subjects were delivered pain alone or with the simultaneous placebo treatment. Findings supported the previous evidence, in that, placebo analgesia was mediated by the opioid receptors' activation in right ACC, dorsolateral PFC (DLPFC), anterior insula and NAcc. Time course of activation, however, was notable, such that increased opioid receptor activation in DLPFC before placebo administration was associated with decreased subjective pain experience, pointing out the top down control of pain experience. Expectancy of pain reduction triggers activation of opioid system in DLPFC, which then results in the attenuation of pain experience through other subcortical functions.

Regulation of the subjective pain experience appeared to be regulated by cognitive control mechanisms. In their disruption theory, Liebarmann et al.[11] suggested that automatic negative affective processes generates subsequent reflective conscious processes that results in the inhibition of very same negative affective processes by the hardwired biofeedback mechanism. The role of ventrolateral PFC, especially lateralized to right, in modulating the negative affect by its projections to dorsal ACC and amygdala. In order to test their hypothesis, they examined the PET scans of patients with IBS (irritable bowel syndrome) during rectal stimulation under either placebo given or active drug conditions. Increased activation was found in right ventrolateral PFC associated with expectancies for the analgesic effects of the treatment. More specifically, increased right ventrolateral PFC activity was followed by the decreased dorsal ACC activity, leading to symptom improvement. Such findings are also important in terms of demonstrating the independence of placebo effect from health improvements due to time course, because, the effects of habituation to rectal stimulation were associated with a different region of ACC from where the placebo effects were observed.

Modality of the pain was also investigated to test whether distinct neural mechanisms are involved in the analgesic effects for thermal pain and shocks [12] however, consistent with previous findings, decreased activity in right ACC, insula; thalamus was associated with decreased subjective reports for both groups. However, brain regions activated during pain anticipation were found to be different from that pain experience. Increased activity in right ACC, OFC, PAG and DLPFC during pain anticipation was associated with subsequent symptom improvement. Findings indicated the role of cognitive control such that top-down regulation of pain initiated by the expectancy of pain reduction that is reflected on the activation of frontal cortices, specifically, ventrolateral PFC and ACC. These regions trigger the functions of the midbrain regions modulating actual pain experience. Pain experience is further monitored by the right ACC through the feedback mechanisms, supporting for the role of cognition in analgesia. Such evidence is also in line with the view arguing for the interactions between prefrontal and cingulate systems mediating the cognitive reappraisal of the meaning of the evocative stimuli $[13,14]$.

Converging evidence has been reported recently by Nemoto and colleagues (2007) in a study examining analgesic responses to thermal pain in healthy subjects who responded to placebo or not [15]. They found similar pattern of activation before the placebo administration such that placebo-responder group showed increased activation of medial PFC and ACC, whereas right ACC activity gradually decreased subsequent to pain stimulation. Placebononresponders showed activations in the same regions with the placebo-responders during preadministration and pain, however, the decreased right ACC activation was not observed, supporting for the role of the neural changes in the anticipation phase in organizing the placebo analgesia.

Overall, such findings point out the role of topdown regulation of placebo analgesia in which expectationinduced changes in prefrontal structures influence the subcortical opioid releasing regions such as PAG and midbrain. This is important in the sense that placebo analgesia is not simply the subjective reports of change, but rather reflected on the objective neural responses involved in the pain experience.

Opioid-related placebo analgesia has been discussed, non-opioid based placebo analgesia has been implicated so far [16]. For example, in their study, Amanzio and Benedetti [17] administered a non-opioid analgesic drug ketolorac for 2 days and on the third day, they replaced the drug with the placebo (saline). On that replacement day, they told subjects that the drug was either an analgesic or just an antibiotic. They found that following administration of naloxone blocked the analgesic effect of placebo only when the subjects were told the drug was an analgesic but not the drug was an antibiotic. In that sense, findings were in line with learning accounts of placebo effect [18]. When contextual cues signaling analgesia were made salient, analgesia could be blocked by the opioid antagonist naloxone, however when the analgesia expectancies were 
eliminated, naloxone could not impair the analgesic effects of placebo.

Placebo analgesia has been discussed in relation with dopaminergic functioning. PET results revealed that higher dopamine release in NAcc during analgesic anticipation was associated with more analgesia expectations in placebo-responders group than nonresponders group [19]. Increased dopaminergic activity was shown to be associated with the anticipation of the reward that is the analgesic outcome which, has been proposed as the core mechanism accounting for the attenuation of the pain experience associated with increased dopamine release. In the next section, the role of dopaminergic functions in mesolimbic pathway is addressed in the context of placebo responses.

\section{Dopaminergic Pathways Involved in Placebo Effect}

The role of dopaminergic activity has been demonstrated in placebo analgesia, however, most of the evidence comes from the placebo research on Parkinson's disease (PD) and psychoactive drugs [20] both of which are characterized by changes in dopamine functions. Parkinson's disease is a motor disorder characterized by the resting tremors, bradykinesia, akinesia, and postural instability. Symptoms are associated with the abnormalities in striatal dopamine functioning, specifically in caudate and putamen significantly less than usual.

A number of studies have demonstrated the placebo effect in a group of PD patients. For example, in a double blind trial of pergolide, a dopamine agonist commonly prescribed for $\mathrm{PD}$, patients in placebo group did improve as much as active-drug pergolide group [21]. Goetz et al.[22] reported consistent evidence for another dopamine agonist drug, ropinirole, in a randomized placebo-controlled study. When groups given placebo and ropinirole were compared, placebo group was found to show $50 \%$ improvement in motor functioning, mostly in bradykinesia and rigidity that are the dopamine-related impairments. Such findings are in line with that placebo-induced symptom improvement in PD is mediated by the dopaminergic functioning. It is important to note that objective versus subjective improvement can be discriminated more precisely in PD compared to conditions of pain or depression, which further indicates concrete mechanisms other than the expectancy-driven experience of well-being [23].

Increased striatal dopamine release was demonstrated in PD patients who expected to receive apomorphine, a DA agonist. PET scans revealed that, compared to control condition, placebo treatment resulted in increased dopamine release specifically in caudate and putamen and placebo group also reported significant objective clinical benefits associated with higher dopamine release in motor striatum [24]. The same research group provided further evidence supporting the clinical improvement associated with increased dopamine release in dorsal striatum. In addition, expectancies for the treatment response were found to be associated with increased dopamine release in ventral striatum [25].

Striatal dopamine function was also demonstrated in a transcranial magnetic stimulation (TMS) study. Patients with PD were told that they had $50 \%$ chance to have real or sham (placebo) treatment, but actually all the patients received the sham treatment. Placebo group showed higher dopamine release in both dorsal and ventral striatum, however, not all of the patients showed symptom improvement. Only the patients with high dopamine concentration in dorsal striatum showed symptom improvement whereas dopamine in ventral striatum was not related to any clinical benefit [26].

Such differentiation in dopaminergic functions of dorsal and ventral striatum is in line with their functional differentiation. Specifically, dorsal striatum is especially involved in voluntary movement whereas ventral striatum modulates functions related to expectancy, motivation and reward anticipation [27]. Accordingly, although placebos act as a reward due to the positive treatment expectancies of patients [23], it is not directly related to symptom improvement [26]. In that sense, placebo induces objective improvements in clinical symptoms through its disease specific effect on dorsal striatum whereas expectancies of healing operate on the reward circuit regulated by the ventral striatum $[25,28]$.

\section{Reward Expectation and Placebo Outcome}

Reward expectation is one way to explain placebo effect observed not only in Parkinson's disease but also in the placebo analgesia [19,29,30]. Martikainen et al. [31] found that the striatal dopamine receptor binding potential six years before predicted analgesia responses of healthy subjects. In the more recent fMRI study, Scott et al. [19] measured the brain activity during reward anticipation and a control task. Also, emotional and behavioral responses to the placebo analgesic and expectancies regarding the drug efficacy were examined. Subjects who showed more NAcc activation during reward anticipation task had also higher expectancy for analgesic outcome. Moreover, the subjects who had more analgesic responses reported the placebo to be more effective than they expected.

Findings are in line with the dopaminergic activity in the brain's reward pathway. The midbrain dopamine cells are grouped in to form three major pathways and the reward circuitry is one of these characterized as originating from the medial parts of ventral tegmental area (VTA) and projecting to mesolimbic cortex [32]. The most important region in terms of reward processing is the ventral striatum, especially the NAcc, where the dopamine cells play critical role in reward expectancy and goal-directed motivated behaviors. Phasic (fastly changing) and tonic (stable or relatively slow changes) dopamine cell firings in ventral striatum are important determinants of reward processing as well.

Dopaminergic activity in ventral striatum represents the anticipation or the prediction of the reward, rather than actual rewards to optimize the organism's goals $[32,33]$. If there is no actual reward, then, how do the placebo drugs trigger the activity of the reward pathway as if actual rewarding stimuli? In clinical cases, healing is the main goal of the treatment, the situational cues in the treatment setting, suggestions for healing, having prior experience with the treatment, (learning experience), even only being the treatment recipient forms a treatment expectancy that signals the reward that is healing. Ventral striatal mechanisms modulate not only such anticipatory mechanisms but also the saliency of the reward [16].

This functional framework was supported in a PET study with healthy participants [34]. Initially, amphetamine was administered in a particular context and then tested how subjects responded to placebo in that particular context. As amphetamine and context were paired, placebo drug was expected to act as the active drug, making the 'reward' salient and activating the stimulus-response chains learned 
in that context. Similar to the expectancy-induced placebo outcomes, dopamine release in NAcc for the placebo condition was found to be no different than it was for the active drug administration.

On the other hand, it has been also argued that reward-related expectancies driven by top-down processes were better predictors of drug effects than simply the conditioning [35]. They provided supporting evidence by simply manipulating the expectancy effects. In their study, healthy subjects were told that they would receive either methylphenidate or placebo. When subjects did expect to receive methylphenidate, they showed lower dopamine release in ventral striatum in response to methylphenidate compared to when they did not expect to receive. More importantly, even naive subjects who had no prior experience of methylphenidate, showed increased dopamine release in NAcc and decreased activity in thalamus and cerebellum, when they expected to receive methylphenidate but they were given the placebo, suggesting for the role of higher-order cortical processes in the regulation of placebo response.

As most of the studies target the link between dopaminergic activity and placebo response in PD, placebos seem to induce disease-specific effects. However, midbrain dopaminergic pathway is involved in the processing of reward in general and its role is not limited to PD but also demonstrated in depression as reviewed in the following section.

\section{Placebo Effect in Depression}

Major depression is another field which placebo effect has been studied extensively. An early metaanalysis [36] on the effectiveness of antidepressants proposed the $75 \%$ effectiveness of the antidepressants is due to the placebo effect, which has further encouraged the placebo controls in antidepressant research. Current findings are exciting because significant placebo-related symptom improvement has been observed in depression, even in severe cases [37,38]. Although such findings underline the ethical and practical questions arise in relation with the prevalent use of antidepressants, however, it is important to understand the dynamics of the placebo effect before discussing it in the context of active drug effects.

Serotonergic system has been implicated as the major mechanism underlying the placebo effect [39-41]. As in cases of pain analgesia and Parkinson's disease, placebos, in depression, result in responses matched with antidepressant effects of serotonin reuptake inhibitors [42] (SSRIs). It is important to note that clinical improvements are significantly different in placebo or antidepressant treatments, there appears to be anatomical differences in regions involved in producing such improvements.

Placebo effect seemed to result from the top-down modulation of treatment expectancies. Prefrontal cortex activity, especially in the cingulate cortex, has been found to determine the treatment response [43] in both placebo and antidepressant treatments, however, in placebo treatments increase in the frontal cortex activity was observed in the very beginning whereas antidepressant-related frontal activation occurs much later throughout the treatment course [33].

Mayberg et al. [40] demonstrated the common and distinguishing mechanisms through the course of 6-week placebo and fluoxetine treatment in a double-blind PET study. Clinical improvement, for both types of treatments, was found to be related to, decreases in subgenual cingulate and thalamus, and also increases in posterior cingulate, and prefrontal cortex. Despite comparable improvement, fluoxetine resulted in decreased activity in hippocampus and striatum, increased activity of brainstem/pons, especially which the latter suggested for the bottom-up regulation of the autonomic nervous system activity. Changes in neural activity induced by fluoxetine were widespread, however, no significant differences were found with respect to changes in depressive symptomology. One explanation may be related to the longevity of the treatment response. In other words, differences in neural activity may determine further improvement in the symptoms or the maintenance of the remission [43]

Functional differences in brain activity were more specifically examined demonstrated in an electroencephalography (EEG) study [44]. Subjects' prefrontal EEG cordance were measured at three time points, at the placebo lead-in phase (1 week pretreatment period), at the beginning of the medication (either antidepressant or placebo) and at the end of the treatment. No clear differences in clinical improvement for placebo and active treatment groups. More importantly, treatment response was determined by the decreases in the EEG cordance at PFC during the placebo leadin phase, which represents the regulatory activity of anterior cingulate cortex. Such findings were in line with previous evidence demonstrating the role of ACC in cognitive modulation of treatment outcomes [10,11,42].

It is also likely that personal expectations formed during the pretreatment phase, the positive interpersonal relations with the medical team might be critical determinants of the improvement [44]. Since medication (either antidepressant or placebo) effects are not apparent in the first week of the treatment, regional neural changes observed during that first week of treatment might reflect the expectancy component of treatment. At the first week, different from the active-drug condition increased ACC activity was observed in the placebo group. On the other hand, activational changes in hippocampus, striatum and brain stem are unique to active-drug condition, which may reflect the long term outcome such as remission. In that sense, especially striatal changes may reflect the reward-related changes before the beginning of the actual treatment. However, despite supporting evidence for PD and analgesia [10,24,35], the role of dopaminergic activity has not been demonstrated so far.

Existing evidence support the comparable effectiveness of placebos as antidepressants along with the associated neural changes. However, there are some important issues that need to be addressed regarding the placebo 'antidepressants'. One of them is the active placebos Kirsch and Sapirstein [36], the drugs that have no specific antidepressant effect but produce certain side effects, such as dry mouth, sedation, as these antidepressants. It has been argued that patients receiving placebos with the expectation of antidepressant may not hold strong positive beliefs regarding the effectiveness of the medication. However, if such patients also experience the specific side effects which they think that the antidepressant drug produce, their positive expectations about the treatment outcome result in greater improvements in depressive symptoms, which in turn increases their use in research and clinical practice. However, it is also likely that use of active placebos may reduce the blindness of the subjects as well as experimenters. Depending on the type or intensity of the sideeffects, subjects may guess the condition in which they are assigned and as blindness is a must especially in placebo research, this may interfere their treatment outcome. Another point is the variability in patients' disease or medication/ treatment histories. Clinical trials on depression rarely include first-episode patients or patients who are naïve to treatment. Prior conditioning or experience with the antidepressants influence the expectancies and inevitably bias the results regarding the treatment efficacy [43]. 
Despite certain limitations, neuroimaging studies have revealed the placebo effect as comparable to active antidepressants [45-47]. Overall, it appears that placebo antidepressants have comparable efficacy to active antidepressants in terms of clinical improvement in depressive symptoms. Similar to the antidepressant functions, placebo treatments act on the serotonergic functions in frontal cortex and the resulting disease specific improvements tend to be modulated by the expectancies of the treatment outcome.

\section{Stress Response in Placebo Effect}

Expectancies of well-being might provide individuals feelings of comfort and drive them to experience less anxiety and stress throughout the treatment. Studies that had stressrelated measures have found evidence accordingly. Studies employing measures of affect or stress provided empirical support. For example, when subjects were given placebo, they were told that either drug does work or not. Expectancies for the drug efficacy were found to be associated with decreased levels of cortisol and less negative thoughts regarding the treatment. Although symptom reduction was no different in two groups, the former group expecting the drug would work experienced less stress during the treatment.

It has also been suggested that perceived stress in treatment setting and placebo responsiveness may be related. Involvement of mesolimbic structures and also reward mechanisms may explain individual differences in placebo responses and the responses of these structures, to a certain extent, are related to individuals' perceptions during the treatment course. Minimal stress experience in the environment and also high treatment expectancies facilitate responsiveness to placebo [45]. However, research in this area is still limited and anxiolytic effect of placebo and its underlying mechanisms are needed to be explored.

\section{Conclusion and Implications for the Future}

Neurological mechanisms underlying placebo effect is relatively a newborn area of research, and there is still much to explore for the future. First of all, the mechanisms underlying individual differences in the placebo response are needed to be explored in more controlled designs. Genetic differences may operate via the higher-order cortical functions, but it is also possible such differences may be a function of the genotypic variation in the neurotransmitter functions. Personality characteristics, such as openness to experience, suggestibility, may moderate placebo responsiveness. Addressing this, future research will not only reveal the traits that enhance or reduce placebo effect but also broaden our understanding regarding the mechanisms underlying placebo response. Last, disease-specific outcomes may be coordinated by different neural mechanisms although treatment expectancy accounts for most of the placebo effect. More specifically, an analgesic drug is expected to show its effect in the short run whereas the effect of antidepressants appears weeks later. Thus, commonalities and distinctions in the neural mechanisms underlying placebo effect need to be specifically examined in the future research.

\section{References}

1. Levine JD, Newton CG, Howard LF. The mechanism of placebo analgesia. Lancet 1978;312: 654-7.

2. Finniss, DG., Kaptchuk TJ, Miller F, Benedetti F. Biological, clinical, and ethical advances of placebo effects. Lancet 2010;375: 686-95.

3. Colloca L, Miller, FG. How placebo responses are formed: A learning perspective. Philos Trans R Soc Lond B Biol Sci 2011;366:1859-69.
4. Benedett F. Placebo effects: from the neurobiological paradigm to translational implications. Neuron 2014;84:62337.

5. Moerman DE. From Meaning, Medicine, and the placebo effect (v.28). Cambridge: Cambridge University Press; 2002.

6. Birch S. A review and analysis of placebo treatments, placebo effects, and placebo controls in trials of medical procedures when sham is not inert. J Altern Complement Med 2006;12: 303-10.

7. Colloca L, Benedetti F. Placebos and painkillers: is mind as real as matter? Nat Rev Neurosci 2005;6:545-52.

8. Tracey I. Getting the pain you expect: Mechanisms of placebo, nocebo and reappraisal effects in humans. Nat Med 2010;16:1277-83.

9. Petrovic P, Kalso E., Petersson KM, Ingvar M. Placebo and opioid analgesia--imaging a shared neuronal network. Scienc. 2002;295:1737-40.

10. Zubieta JK, Bueller JA., Jackson LR, Scott DJ, Xu Y, Koeppe RA. Placebo effects mediated by endogenous opioid activity on $\mu$-opioid receptors. J Neurosci 2005;25:7754-62.

11. Lieberman MD, Jarcho JM, Berman S, Naliboff BD, Suyenobu BY, Mandelkern M, et al. The neural correlates of placebo effects: A disruption account. Neuroimage 2004; 22 : 447-55.

12. Wager TD, Rilling, JK, Smith EE, Sokolik A, Casey KL, Davidson RJ, et al. Placebo-induced changes in fMRI in the anticipation and experience of pain. Science 2004;303:11627.

13. Ochnser KN, Gross JJ. The cognitive control of emotion. Trends Cogn Sci 2005;9: 242-9.

14. Etkin A, Egner T, Kalisch R. Emotional processing in anterior cingulate and medial prefrontal cortex. Trends Cogn Sci 2011;15: 85-93.

15. Nemoto H, Nemoto Y, Toda H, Mikuni M, Fukuyama H. Placebo analgesia: A PET study. Exp Brain Res 2007;179:655-64

16. Benedetti F. How the doctor's words affect the patient's brain. Eval Health Prof 2002;25:369-86.

17. Amanzio M, Benedetti F. Neuropharmacological dissection of placebo analgesia: expectation-activated opioid systems versus conditioning-activated specific subsystems. J Neurosci 1999;19:484-94.

18. Montgomery, GH, Kirsch I. Classical conditioning and the placebo effect. Pain1997:72:107-13.

19. Scott DJ, Stohler CS, Egnatuk CM, Wang H, Koeppe RA, Zubieta JK. Individual differences in reward responding explain placebo-induced expectations and effects. Neuron 2007;55: 325-36.

20. Faria V, Fredrikson M, Furmark T. Imaging the placebo response: A neurofunctional review. Eur Neuropsychopharmacol 2008;18:473-85.

21. Diamond SG, Markham CH, Treciokas, LJ. Double blind trial of pergolide for Parkinson's disease. Neurology 1985;35: 291-5.

22. Goetz CG, Leurgans S, Raman R, Stebbins GT. Objective changes in motor function during placebo treatment in PD. Neurology 2000;54:710-4.

23. Lindstone SCC, Stoessl AJ. Understanding the placebo effect: contributions from neuroimaging. Mol Imaging Biol 2007;9: 176-85.

24. de la Fuente-Fernández R, Lu JQ, Sossi V, Jivan S, Schulzer $\mathrm{M}$, Holden JE, et al. Biochemical variations in the synaptic level of dopamine precede motor fluctuations in Parkinson's disease: PET evidence of increased dopamine turnover. Ann Neurol 2001;49:298-303.

25. de la Fuente-Fernández R, Phillips AG, Zamburlini M, Sossi $\mathrm{V}$, Calne DB, Ruth TJ, et al. Dopamine release in human ventral striatum and expectation of reward. Behav Brain Res 2002;136: 359-63.

26. Strafella AP, Ko JH, Monchi O. Therapeutic application of transcranial magnetic stimulation in Parkinson's disease: The contribution of expectation. Neuroimage 2006;31:1666-72.

27. Kirsch I. Response expectancy theory and application: A decennial review. Appl Prev Psychol 1997;6:69-79. 
28. Lindstone SC, Schulzer M, Dinelle K, Mak E, Sossi V, Ruth $\mathrm{TJ}$, et al. Effects of expectation on placebo-induced dopamine release in Parkinson disease. Arch Gen Psychiatry 2010;67:857-65.

29. Zubieta J, Smith YR, Bueller JA, Xu Y, Kilbourn MR, Jewett $\mathrm{DM}$, et al. $\mu$-Opioid receptor-mediated antinociceptive responses differ in men and women. J Neurosci 2002;22:5100-7.

30. Zubieta, J, Smith YR, Bueller JA, Xu Y, Kilbourn MR, Jewett DM, et al. Regional mu opioid receptor regulation of sensory and affective dimensions of pain. Science 2001;293: 311-5.

31. Martikainen IK, Hagelberg $\mathrm{N}$, Mansikka $\mathrm{H}$, Hietala $\mathrm{J}$, Någren $\mathrm{K}$, et al. Association of striatal dopamine D2/D3 receptor binding potential with pain but not tactile sensitivity or placebo analgesia. Neurosci Lett 2005;376: 149-53.

32. de la fuente-Fernández R, Stoessl AJ. The placebo effect in Parkinson's disease. Trends Neurosci 2002;25:302-6.

33. Lindstone, SC, Stoessl AJ. Understanding the placebo effect: Contributions from neuroimaging. Mol Imaging Biol 2007;9:176-85.

34. Boileau I, Dagher A, Leyton M, Welfeld K, Booij L, Diksic, $\mathrm{M}$, et al. Conditioned dopamine release in humans: a positron emission tomography [11C] raclopride study with amphetamine. J Neurosci 2007;27: 3998-4003.

35. Volkow ND, Wang GJ, Ma Y, Fowler JS, Wong C, Jayne M et al. Effects of expectation on the brain metabolic responses to methylphenidate and to its placebo in non-drug abusing subjects. Neuroimage 2006;32:1782-92.

36. Kirsch I, Sapirstein G. Listening to Prozac but hearing placebo: A meta-analysis of antidepressant medication. Prevention \& Treatment. 1998;1: Article 2a. [http://citeseerx.ist.psu.edu/viewdoc/download?doi=10.1.1.5 $30.8857 \&$ rep=rep $1 \&$ type $=$ pdf]

37. Ioviena N, Papakostas GI. Correlation between different levels of placebo response rate and clinical trial outcome in major depressive disorder: a meta-analysis. J Clin Psychiatry 2012;73: 1300-6.

38. Khan A, Brown, WA. Antidepressants versus placebo in major depression: an overview. World Psychiatry 2015;14:294-300.

39. Mayberg HS, Brannan SK, Tekell JL, Silva JA, Mahurin RK, et al. Regional metabolic effects of fluoxetine in major depression: Serial changes and relationship to clinical response. Biol Psychiatry 2000;48: 830-43.

40. Mayberg HS, Silva JA, Brannan SK, Tekell J, Mahurin RK. Helen S, et al. The functional neuroanatomy of the placebo effect. Am J Psychiatry 2002;159:728-37.

41. Schulz, V. Clinical trials with hypericum extracts in patients with depression-results, comparisons, conclusions for therapy with antidepressant drugs. Phytomedicine 2002;9:468-74.

42. Wager TD, Rilling JK., Smith EE, Sokolik A, Casey KL, Davidson RJ, et al. Placebo-induced changes in fMRI in the anticipation and experience of pain. Science 2004; 303: 1162-7.

43. Benedetti F, Mayberg HS, Wager TD, Stohler CS, Zubieta JK. Neurobiological mechanisms of the placebo effect. J Neurosci 2005; 25:10390-402.

44. Hunter AM, Leuchter AF, Morgan ML, Cook IA. Changes in brain function (quantitative EEG cordance) during placebo lead-in and treatment outcomes in clinical trials for major depression. Am J Psychiatry 2006;163:1426-32.

45. Oken, BS. Placebo effects: Clinical aspects and neurobiology. Brain 2008;131: 2812-23.

46. Mischoulon D, Price LH, Carpenter LL, Tyrka AR, Papakostas GI, Baer L, et al. A double-blind, randomized, placebo-controlled clinical trial of S-adenosyl-L-methionine (SAMe) versus escitalopram in major depressive disorder. J Clin Psychiatry 2014;75:370-6.

47. Rutherford, BR, Roose SP. A model of placebo response in antidepressant clinical trials. Am J Psychiatry 2013;170:72333. 